\title{
Meningitis recurrente por Streptococcus pneumoniae en una niña con un implante coclear y traumatismo craneoencefálico a pesar de haber recibido la vacuna neumocócica conjugada de 13 serotipos
} Recurrent meningitis by Streptococcus pneumoniae in a girl with cochlear
implant and head trauma despite 13-valent conjugated pneumococcal vaccine

\author{
Dra. Melike Emiroglua, Dra. Gulsum Alkan ${ }^{a}$, Dr. Bahadır Feyzioglu ${ }^{b}$, Biol. Ahmet E. Aycan ${ }^{c} y$
} Dr. Mehmet Ceyhan ${ }^{c}$

\begin{abstract}
RESUMEN
La meningitis bacteriana recurrente es un fenómeno muy poco frecuente en los niños. Las fracturas de la base del cráneo y los implantes cocleares son factores predisponentes importantes, y el agente aislado con mayor frecuencia es el Streptococcus pneumoniae. La implementación de la vacuna neumocócica conjugada de 13 serotipos (VNC13) redujo la incidencia de enfermedades neumocócicas invasivas. La incidencia de enfermedades neumocócicas intercurrentes en pacientes vacunados suele estar relacionada con afecciones predisponentes preexistentes. En este artículo, presentamos un caso de meningitis neumocócica recurrente en una paciente con un implante coclear que sufrió un traumatismo craneoencefálico luego de haber recibido la vacunación completa con la VNC13. La paciente tuvo tres episodios de meningitis en el transcurso de un año. Se detectó la presencia de S. pneumoniae en el cultivo de líquido cefalorraquídeo (LCR) en el primer y tercer episodios, y mediante la prueba de reacción en cadena de la polimerasa (PCR, por su sigla en inglés) en el segundo episodio. Se realizó una intervención neuroquirúrgica luego del tercer episodio de meningitis, y la paciente no tuvo problemas de recurrencias durante los siguientes dos años. Hasta donde sabemos, en la bibliografía no se han descrito casos de meningitis de serotipo 1 por S. pneumoniae luego delainmunización completa con PCV13. Palabras clave: Streptococcus pneumoniae, meningitis recurrente, traumatismo craneoencefálico, vacunación, niño, niña.
\end{abstract}

http:/ / dx.doi.org/10.5546/ aap.2019.e373

Texto completo en inglés:

http:/ / dx.doi.org/10.5546/ aap.2019.eng.e373

a Facultad de Medicina de Selçuk Üniversitesi,

Departamento de Infectología Pediátrica, Konya, Turquía.

b. Facultad de Medicina de Necmettin Erbakan Üniversitesi, Departamento de Microbiología Médica, Konya, Turquía.

c. Departamento de Infectología Pediátrica de Hacettepe Üniversitesi, Ankara, Turquía.

Correspondencia:

Dra. Gulsum Alkan: galkan-85@hotmail.com

Financiamiento: Ninguno

Conflicto de intereses: Ninguno que declarar.

Recibido: 9-3-2018

Aceptado: 21-1-2019
Cómo citar: Emiroğlu M, Alkan G, Feyzioğlu B, Aycan AE, Ceyhan M. Meningitis recurrente por Streptococcus pneumoniae en una niña con un implante coclear y traumatismo craneoencefálico a pesar de haber recibido la vacuna neumocócica conjugada de 13 serotipos. Arch Argent Pediatr 2019;117(4):e373-e376.

\section{INTRODUCCIÓN}

En el neumococo Streptococcus pneumoniae (S. pneumoniae) se han descrito más de 91 serotipos basados en la estructura de las cápsulas polisacarídicas. Aproximadamente 13 serotipos son responsables de más del $75 \%$ de las enfermedades neumocócicas invasivas (ENI), tales como la meningitis, la sepsis, la neumonía y la bacteriemia en niños. ${ }^{1}$ Los distintos serotipos muestran diferencias en la expresión clínica de la enfermedad. Se desconoce si la gravedad de la enfermedad es el resultado del tipo de cápsula o de otros factores de virulencia. ${ }^{2}$ S. pneumoniae es el agente de meningitis bacteriana más frecuente en pacientes con pérdida de líquido cefalorraquídeo (LCR) e implantes cocleares. ${ }^{3}$ Las vacunas neumocócicas conjugadas son muy eficaces para prevenir enfermedades graves, incluida la meningitis, las hospitalizaciones e incluso la muerte. La vacuna neumocócica conjugada de 7 serotipos (VNC7), que incluye los serotipos $4,6 \mathrm{~B}, 9 \mathrm{~V}, 14,18 \mathrm{C}, 19 \mathrm{~F}$ y $23 \mathrm{~F}$, se introdujo en el calendario nacional de vacunación de Turquía en 2009. En 2011, se la remplazó por la VNC13, que incluye también los serotipos 1, 3, 5, 6A, 7F y 19A. En un estudio multicéntrico realizado en Turquía (2010), las tasas de cobertura de la VNC7, VNC10 y VNC13 para la meningitis bacteriana fueron del $48,1 \%, 85,2 \%$ y $92,3 \%$, respectivamente, en todos los grupos etarios. ${ }^{4}$ A pesar de la eficacia de la vacuna, se observó fallo vacunal (FV) en niños con enfermedades predisponentes preexistentes. Aquí se presenta un caso de meningitis neumocócica recurrente causada por 
el serotipo 1 en una niña con implantes cocleares y traumatismo craneoencefálico, quien había recibido la vacunación completa.

\section{A propósito de un caso}

Una niña de 4,5 años tuvo fiebre, cefalea y somnolencia. Cuando tenía 18 meses, a la niña se le colocó un implante coclear con posicionador, ya que tenía malformaciones en el oído interno derecho. Sufrió un traumatismo craneoencefálico sin otorrea ni rinorrea. En la imagen de la tomografía cerebral, se observó una fractura lineal en el hueso occipital derecho. Seis meses después del traumatismo, la paciente tuvo el primer episodio de meningitis (a los 4 años de edad) debido a S. pneumoniae sensible a la penicilina, el cual fue detectado en un cultivo de LCR. Si bien ya se le había administrado la vacuna VNC13 a los 2, 4, 6 y 12 meses de edad, recibió una dosis de PPV23 tras el primer episodio de meningitis neumocócica.

Durante el examen físico de ingreso, los signos de irritación meníngea y el papiledema eran positivos, en tanto que los demás signos eran normales. En el segundo día de hospitalización, se realizó una punción lumbar. En los análisis de líquido cefalorraquídeo (LCR), se observó un valor de 100 células $/ \mathrm{mm}^{3}$ con neutrofilia; las concentraciones de proteínas y glucosa eran de $21 \mathrm{mg} / \mathrm{dl}$ y $53 \mathrm{mg} / \mathrm{dl}$, respectivamente. Los datos

Figura 1. Pérdida de LCR que se origina en la región petrooccipital hacia el oído medio

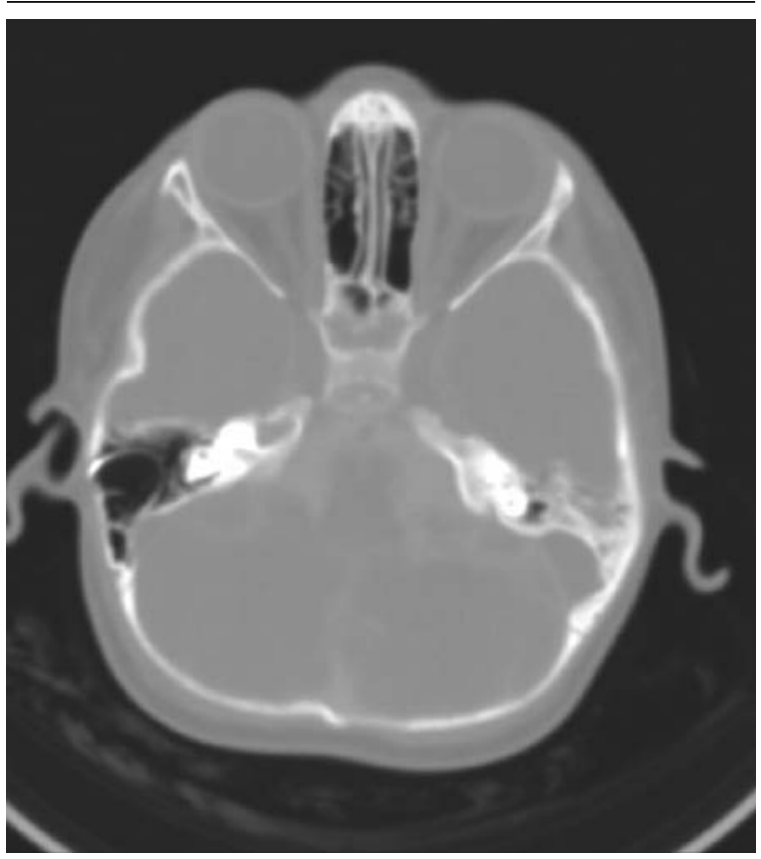

primarios de laboratorio fueron los siguientes: recuento de leucocitos $32600 / \mathrm{mm}^{3}$, neutrófilos $93 \%$; hemoglobina $11 \mathrm{~g} / \mathrm{dl}$; plaquetas $411000 /$ $\mathrm{mm}^{3}$; velocidad de sedimentación globular (VSG) $36 \mathrm{~mm} / \mathrm{h}$ y proteína C-reactiva (PCR) $95 \mathrm{mg} / 1$. Si bien el cultivo de LCR dio negativo, la PCR de LCR fue positiva para S. pneumoniae. La paciente recibió ceftriaxona y vancomicina durante 14 días. La cisternografía por tomografía computada luego del tratamiento fue normal.

Seis meses después (a los 5 años de edad), la paciente volvió a ser hospitalizada con fiebre, cefalea y vómitos. El examen físico era normal, pero presentaba rigidez en el cuello e irritabilidad. El recuento del LCR era de 1000 neutrófilos $/ \mathrm{mm}^{3}$, y las concentraciones de proteínas y glucosa eran de $219 \mathrm{mg} / \mathrm{dl}$ y $12 \mathrm{mg} / \mathrm{dl}$, respectivamente. Los resultados del hemograma fueron los siguientes: leucocitos $32000 / \mathrm{mm}^{3}$ con $85 \%$ de neutrófilos, VSG $36 \mathrm{~mm} / \mathrm{h}$ y PCR $94 \mathrm{mg} / \mathrm{l}$. Inicialmente, la paciente recibió vancomicina y ceftriaxona. En el cultivo de LCR, se observó una proliferación de $S$. pneumoniae sensible a la penicilina. Se administró ceftriaxona durante 14 días.

El tratamiento de los 3 episodios de meningitis fue satisfactorio, sin complicaciones. Los estudios de LCR de control fueron normales tras dos semanas de tratamiento. Las cepas aisladas del primer y tercer episodios de meningitis de la paciente se identificaron como serotipo 1 mediante la reacción de Quellung con antisueros específicos para el serotipo (Statens Serum Institut, Copenhague, Dinamarca).

Las pruebas de detección inmunológica (recuento de glóbulos, recuento de linfocitos en sangre periférica, concentración de inmunoglobulina total en suero, análisis de dihidrorodamina, sistema del complemento) fueron normales; el análisis ELISA para la detección del virus de inmunodeficiencia humana fue negativo. El valor de IgG antineumocócica total fue de $2,8 \mathrm{mcg} / \mathrm{ml}$.

En la ecografía abdominal, se confirmó la presencia del bazo. Se volvió a realizar una cisternografía por RM, y se confirmó la pérdida de LCR que se originaba en la región petro-occipital y se dirigía hacia el oído medio (Figura 1). Una vez que se completó la antibioticoterapia, se llevó a cabo la reparación quirúrgica. Durante los dos años siguientes, la paciente no tuvo recurrencias.

\section{DISCUSIÓN}

La meningitis bacteriana recurrente (MBR) se define como la presencia de dos o más 
episodios de meningitis piógena separados por un período de convalecencia y la resolución completa de todos los signos. Si bien la presencia de una conexión fistulosa entre la flora nasofaríngea y el espacio del LCR tras un traumatismo craneoencefálico representa un riesgo significativo para la meningitis recurrente, las anomalías anatómicas, en especial en el oído interno, los implantes cocleares y los trastornos de inmunodeficiencia son otros factores predisponentes importantes. ${ }^{5}$ S. pneumoniae es el agente causante más frecuente en la meningitis bacteriana recurrente luego de un traumatismo craneoencefálico, seguido de $H$. influenzae y $N$. meningitidis. ${ }^{6}$

Los distintos serotipos de S. pneumoniae muestran diferencias en la expresión clínica de la enfermedad. En concreto, se considera que el serotipo 1 es altamente invasivo y provoca más casos de neumonía bacteriémica que de meningitis. ${ }^{7}$ Existen conexiones claras entre algunos serotipos de neumococos y compromisos orgánicos, tales como la relación entre los serotipos 1, 3, 14, 15, 19A, 33 y la neumonía necrosante y el empiema. No obstante, en ningún estudio se encontró una relación entre un serotipo en particular y la meningitis por pérdida de LCR o una anomalía en el oído interno. ${ }^{8}$

Las VNC son sumamente eficaces para la prevención de ENI causadas por los serotipos incluidos en las vacunas. El FV es infrecuente, independientemente de la vacuna o del calendario de vacunación. Von Mollendorf y cols., informaron que la enfermedad causada por el serotipo 1 prácticamente desapareció en la población pediátrica luego del lanzamiento de la VNC13.7

Enfermedad intercurrente tras la vacunación se define como la presencia de meningitis neumocócica con serotipos de la VNC en un niño que haya recibido una o más dosis de $\mathrm{VNC}$, y la FV se define como un subgrupo de casos con enfermedad recurrente que se presenta en niños que hayan terminado la serie de VNC. ${ }^{9} \mathrm{De}$ 2003 a 2013, Godot y cols., realizaron un estudio sobre la meningitis neumocócica recurrente tras el lanzamiento de las VNC en Francia. Los casos de meningitis intercurrente tras la vacunación fueron del 3,2 \% (era de la VNC7: 24 de 943; era de la VNC13: 15 de 290) y la FV fue del 0,6\% (era de la VNC7: 6 de 943; era de la VNC13: 2 de 290). ${ }^{9}$ Los casos de enfermedad intercurrente tras la vacunación pueden ser el resultado de la patogenia de la infección o la capacidad de respuesta del sistema inmunitario a la vacuna. Las vacunas conjugadas son muy eficaces para las enfermedades graves, como la bacteriemia y las infecciones locales. No fue posible lograr la protección total de las ratas con la vacunación contra la meningitis al inocular las bacterias directamente en el oído interno. ${ }^{10-11}$

Hay una variación significativa en la respuesta inmunitaria serotipo específica a la VNC. En el estudio de Barrow y colaboradores, se midieron los anticuerpos serotipo específicos en 107 niños que habían recibido la VNC7. Ocho niños no pudieron producir una respuesta contra el serotipo infectante $(4,6 B$ [n = 4], 14, 18C [n = 2]) a pesar de haber recibido al menos 3 dosis de la vacuna. ${ }^{12}$ Es posible que este fenómeno sea el resultado de grandes cargas de polisacáridos neumocócicos que reducen la población de células B de memoria y provocan una parálisis inmunológica, o una base genética posible que genera una falta de respuesta a serotipos neumocócicos individuales. ${ }^{13}$

Además, en los pacientes con MBR se considera que la comorbilidad es elevada en los casos de FV, pero los datos son limitados. Godot y colaboradores informaron que solo 10 de 47 pacientes con MBR y enfermedad intercurrente tras la vacunación tenían fisuras de las meninges ( 2 congénita y 2 tras un traumatismo), implante coclear $(n=1)$, inmunodeficiencias $(n=5)$. De estos 10 pacientes, la causa más frecuente fue el serotipo 19F $(n=6)$, incluso luego del lanzamiento de VNC13. En el estudio también se identificaron los siguientes serotipos: $6 \mathrm{~B}(\mathrm{n}=2), 4(\mathrm{n}=1)$, $23 \mathrm{~F}(\mathrm{n}=1) \cdot{ }^{9} \mathrm{Li}$ y colaboradores informaron un caso de meningitis neumocócica recurrente de serotipo $23 \mathrm{~F}$ en un niño con pérdida de LCR luego de haber recibido la vacunación completa de VNC13. ${ }^{14}$

Se pueden utilizar diferentes técnicas para detectar o localizar fístulas de LCR. La cisternografía tiene una sensibilidad del $92 \%$ y una especificidad del $100 \%$. Las principales desventajas de la tomografía computada son su resolución espacial deficiente si se la compara con las tomografías computadas de alta resolución y la ausencia de detalles óseos.

La RM detecta de manera precisa las pérdidas de LCR y las complicaciones asociadas, tales como el encelofacele y el meningocele. Puede que esta sea la causa de demora en el diagnóstico en nuestra paciente. ${ }^{15}$

Asumimos que nuestra paciente tuvo un FV, ya que sufrió meningitis recurrente por serotipo 1 
a pesar de haber recibido la vacunación completa de VNC13 y VPN que cubre el serotipo 1. La infección se diseminó desde el oído medio hacia el área subaracnoidea. Lamentablemente, no se pudo determinar la concentración de anticuerpos serotipo específicos ni obtener un cultivo del oído medio.

Al momento de evaluar a un niño con meningitis recurrente, se deben examinar los factores predisponentes para detectar pérdidas de LCR, inmunodeficiencia o dispositivos internos, independientemente del estado de inmunización del paciente.

\section{REFERENCIAS}

1. Cohen R, Biscrdi S, Levy C. The multifaceted impact of pneumococcal conjugate vaccine implementation in children in France between 2001 to 2014. Hum Vaccin Immunother. 2016; 12(2):277-84.

2. Lynch JP 3rd, Zhanel GG. Streptococcus pneumoniae: Epidemiology, Risk Factors, and Strategies for Prevention. Semin Respir Crit Care Med. 2009; 30(2):189-209.

3. Santos SF, Rodrigues F, Dias A, Costa JA, et al. Meningite bacteriana pós-traumática em idade pediátrica: análise de onze anos. Acta Med Port. 2011; 24(3):391-8.

4. Ceyhan M, Yildirim I, Sheppard CL, George RC. Pneumococcal serotypes causing pediatric meningitis in Turkey: application of a new technology in the investigation of cases negative by conventional culture. Eur I Clin Microbiol Infect Dis. 2010; 29(3):289-93.

5. Ghosh A, Sharma S, Halder PP, Bhattacharya A, Mukherjee S. Diagnostic Dilemma in a 15-Year-Old Boy with Recurrent Pneumococcal Meningitis. J Clin Diagn Res. 2017; 11(5):SD03-4.
6. Tebruegge M, Curtis N. Epidemiology, etiology, pathogenesis, and diagnosis of recurrent bacterial meningitis. Clin Microbiol Rev. 2008; 21(3):519-37.

7. von Mollendorf C, Cohen C, Tempia S, Meiring S, et al. Epidemiology of serotype 1 invasive pneumococcal disease, South Africa, 2003-2013. Emerg Infect Dis. 2016; 22(2):261-70.

8. Bender JM, Ampofo K, Korgenski K, Daly J, et al. Pneumococcal necrotizing pneumonia in utah: does serotype matter? Clin Infect Dis. 2008; 46(9):1346-52.

9. Godot C, Levy C, Varon E, Picard C, et al. Pneumococcal meningitis vaccine breakthroughs and failures after routine 7-valent and 13-valent pneumococcal conjugate vaccination in children in France. Pediatr Infect Dis J. 2015; 34(10):e260-3.

10. O'Mahony LN, Klein EJ, Walker W. A fully immunized child with a cochlear implant and streptococcus pneumoniae meningitis 3 years after implantation. Pediatr Emerg Care. 2011; 27:(3):200-2.

11. Sjöström K, Spindler C, Ortqvist A, Kalin M, et al. Clonal and capsular types decide whether pneumococci will act as a primary or opportunistic pathogen. Clin Infect Dis. 2006; 42(4):451-9.

12. Borrow $R$, Stanford $E$, Waight $P$, Helbert $M$, et al. Serotypespecific immune unresponsiveness to pneumococcal conjugate vaccine following invasive pneumococcal disease. Infect Immun. 2008; 76(11):5305-9.

13. Stanford E, Ladhani S, Slack M, Scott D, et al. Pneumococcal serotype-specific unresponsiveness in vaccinated child with cochlear implant. Emerg Infect Dis. 2012; 18(6):1024-6.

14. Li YC, Chen CY, Wu KH, KuoHT, Wu HP. Recurrent Streptococcus Pneumoniae $23 \mathrm{~F}$ meningitis due to cerebrospinal fluid leakage from the ear cannel: a case report. $B M C$ Pediatr. 2015; 15:195.

15. Vemuri NV, Karanam LSP, Manchikanti V, Dandamudi $\mathrm{S}$, et al. Imaging review of cerebrospinal fluid leaks. Indian J Radiol Imaging. 2017; 27(4):441-6. 